\title{
Systematic review and meta-analysis of prevalence studies in transsexualism
}

Jon Arcelus, $\mathrm{MD}, \mathrm{PhD}^{1,2}$, Walter Pierre Bouman $\mathrm{MD}^{1}$, Wim Van Den Noorgate $\mathrm{PhD}^{3}$, Laurence Claes, $\mathrm{PhD}^{4}$, Gemma Witcomb $\mathrm{PhD}^{2}$, \& Fernando Fernandez-Aranda $\mathrm{PhD}^{5,6}$

${ }^{1}$ Nottingham Centre for Gender Dysphoria, Nottingham, United Kingdom

${ }^{2}$ School of Sport, Exercise, and Health Sciences, Loughborough University, United Kingdom

${ }^{3}$ Centre for Methodology of Educational Research, Katholieke Universiteit, Leuven, Belgium

${ }^{4}$ Faculty of Psychology and Educational Sciences, KU Leuven, Leuven, Belgium

${ }^{5}$ Department of Psychiatry, University Hospital of Bellvitge-IDIBELL, Barcelona, Spain

${ }^{6}$ CIBER Fisiopatología Obesidad y Nutrición (CIBERobn), ISCIII, Barcelona, Spain

\section{Corresponding author:}

Dr Walter Pierre Bouman

Nottingham Centre for Gender Dysphoria

Nottinghamshire Healthcare NHS Trust

3 Oxford Street

Nottingham, NG1 5BH

United Kingdom

Telephone: +44(0)1158760160

Fax: +44(0)115947 5609

walterbouman@doctors.org.uk 
Conflict of Interest: The authors have no relevant conflict of interest to declare.

\section{Statement of Authorship}

Category 1

(a) Conception and Design

Jon Arcelus, Laurence Claes; Walter Pierre Bouman; Gemma Witcomb; Wim Van Den Noorgate

(b) Acquisition of Data

Jon Arcelus; Gemma Witcomb

(c) Analysis and Interpretation of Data

Jon Arcelus; Wim Van Den Noorgate; Laurence Claes

Category 2

(a) Drafting the Article

Jon Arcelus; Walter Pierre Bouman; Laurence Claes; Gemma Witcomb;

Fernando Fernandez-Aranda

(b) Revising it for Intellectual Content

Jon Arcelus; Walter Pierre Bouman; Laurence Claes; Gemma Witcomb ;

Fernando Fernandez-Aranda

\section{Category 3}

(a) Final Approval of the Completed Article

Jon Arcelus; Walter Pierre Bouman; Wim Van Den Noorgate; Laurence Claes; Gemma Witcomb; Fernando Fernandez-Aranda 


\section{Abstract}

Background: Over the last 50 years several studies have provided estimates of the prevalence of transsexualism. The variation in reported prevalence is considerable and may be explained by factors such as the methodology and diagnostic classification used and the year and country in which the studies took place. Taking these into consideration, this study aimed to critically and systematically review the available literature measuring the prevalence of transsexualism as well as performing a metaanalysis using the available data.

Methods: Databases were systematically searched and 1473 possible studies were identified. After initial scrutiny of the article titles and removal of those not relevant, 250 studies were selected for further appraisal. Of these, 211 were excluded after reading the abstracts and a further 18 after reading the full article. This resulted in 21 studies on which to perform a systematic review, with only 12 having sufficient data for meta-analysis. The primary data of the epidemiological studies were extracted as raw numbers. An aggregate effect size, weighted by sample size, was computed to provide an overall effect size across the studies. Risk ratios and 95\% confidence intervals (CIs) were calculated. The relative weighted contribution of each study was also assessed.

Results: The overall meta-analytical prevalence for transsexualism was 4.6 in 100,000 individuals; 6.8 for trans women and 2.6 for trans men. Time analysis found an increase in reported prevalence over the last 50 years.

Conclusions: The overall prevalence of transsexualism reported in the literature is increasing. However, it is still very low and is mainly based on individuals attending clinical services and so does not provide an overall picture of prevalence in the general population. However, this study should be considered as a starting point and 
the field would benefit from more rigorous epidemiological studies acknowledging current changes in the classification system and including different locations worldwide.

Keywords: Gender Dysphoria, transgender, population, systematic review, metaanalysis 


\section{Introduction}

Transsexualism, as defined by the International Classification of Disease (ICD-10) ${ }^{(1)}$ and the previous editions of the Diagnostic and Statistical Manual of Mental Disorders $^{(2,3)}$, describes individuals who experience discomfort or distress caused by the discrepancy between their gender identity and the sex they were assigned at birth. When this distress is sufficiently intense individuals wish to transition from one point on a notional gender scale to another - most commonly from a man to a woman (people known as trans women) or from a woman to a man (people known as trans men ${ }^{(4,5)}$. The diagnosis of transsexualism according to the ICD- $10^{(1)}$ is currently under revision. It is proposed that the new edition of the ICD (ICD-11) will include a new diagnostic term and will also include individuals who do not fit into the gender binary category ${ }^{(6)}$, as is the case in the DSM- $5^{(7)}$.

\section{To estimate the prevalence of trans individuals is relevant for health service} development and policymaking, although this can be complex due to several factors. Some of those factors relate to the complexity of undertaking general prevalence studies, i.e. the fact that diagnoses change over the years or that results differ depending on the period of time used to collect data. For example, point prevalence is a measure of the proportion of people in a given population at an exact time point, such as a particular date, which is in contrast to period prevalence that measures the proportion of people in a given population over a specific time period, for example several years ${ }^{(8)}$.

Other factors that also add to the complexity of undertaking epidemiological studies relate to the subject studied; in this case the number of transsexual individuals in the 
community. For example, the terminology and classification systems used have varied over the years, and authors have used some of this terminology inconsistently, for example, Gender Identity Disorder, Gender Dysphoria, or Transsexualism.

Nevertheless, it is reassuring (in relation to performing this meta-analysis) to find that there are many epidemiological studies that have used the term "transsexualism" and which have followed the ICD or DSM diagnostic criteria $(9,1,2,3,10,11,7)$ or the definition developed by Benjamin in $1966^{(12)}$, which requires all of the following:

1) A sense of belonging to the opposite sex, of having been born into the wrong sex, or being one of nature's extant errors.

2) A sense of estrangement from one's own body: all indications of sex differentiation are considered as afflictions and repugnant.

3) A strong desire to resemble physically the opposite sex via therapy, including surgery.

4) A desire to be accepted by the community as belonging to the opposite sex.

The definition of transsexualism is different in the DSM-IIIR ${ }^{(3)}$. This edition of the diagnostic criteria did not include those individuals who were not interested in undergoing sex reassignment surgery and who received the alternative diagnosis of Gender Identity Disorder of Adolescents and Adulthood, Nontranssexual Type (GIDAANT). This great variation in how transsexualism is defined in different studies (based on the diagnostic criteria used at the time that the study took place) will clearly affect the reported prevalence. 
A second complexity in developing true epidemiological studies of transsexualism relates to the methods used to identify this population. For example, the country where the study takes place can influence the prevalence of individuals found, as trans people tend to live in larger cities and especially in areas, or countries, which are defined as "trans friendly"(13). Therefore studies from specific countries may describe a high prevalence of transsexual individuals, which may not be generalizable to other countries. Thirdly, the timing of the study may also affect the findings. The fact that in some countries tolerance to trans individuals has improved over the years has allowed trans people to "come out" more easily in order to access clinical services ${ }^{(14,}$ 15). This may be reflected by the fact that older studies ${ }^{(16)}$ report lower prevalence than more recent ones ${ }^{(17)}$. Finally, the recruitment process used to collect epidemiological data will also influence the findings. Many studies are based on clinical populations of individuals which, by definition, only include those who have the capacity and motivation to ask for help, but, importantly, can also access clinical services ${ }^{(18)}$. This is reflected in the large number of studies from the Netherlands ${ }^{(18,19)}$ where trans services have been available for many years and where society is generally tolerant $^{(14,15)}$.

Therefore, as highlighted by the WPATH Standards of Care ${ }^{(20)}$ and other authors ${ }^{(21)}$ efforts to formally calculate the prevalence of transsexualism present with enormous difficulties, due to the differences in cultural manifestation of gender behavior. It is because of this that researchers who have studied prevalence rates have focused on the most easily counted subgroup of gender-nonconforming people - those who present for gender-transition-related care at specialist gender identity clinics ${ }^{(21)}$. As a consequence many prevalence studies published in this field have their origins in the 
Western world ${ }^{(22)}$. There is only one prevalence study from the Eastern world ${ }^{(23)}$, which is surprising given that many countries like Thailand, India and Pakistan are known to have an apparently tolerant culture towards trans* identities, although there are many ethnographic related studies ${ }^{(24,25,26)}$.

The large number of studies investigating prevalence of transsexual individuals, and reviewed in this study, provide the best available insight into the rates of transsexualism, and vary from $0.45^{(22)}$ to $23.6^{(23)}$ per 100,000 people. Although prevalence studies are welcome, such a great variation in findings leaves the reader confused. Therefore, the aim of this study was to respond to the reported variation in prevalence by critically and systematically reviewing prevalence studies in transsexualism. Where data were available, a meta-analysis of the studies was carried out which took population, diagnosis, the time period studied and gender into consideration.

\section{Methods}

\subsection{Search strategy}

This meta-analytic review adheres to the guidelines detailed in the PRISMA Statement ${ }^{(27)}$. A systematic literature search, appraisal and meta-analysis was conducted using a broad range of subject headings in order to identify relevant prevalence studies in the field. The following data bases were used: Web of Sciences, Medline/Pubmed, Biosis, Science Direct, and Scielo. For each database, combinations of the following search components were used: Transsexual, Transgender, Gender Dysphoria, Gender Identity Disorder, Gender non conforming, Gender Variant, epidemiology, incidence, and prevalence. Studies published between 1945 and June 
2014 were selected. Two researchers independently selected the studies, extracted the data, cross-checked them and resolved disagreements. Case studies or studies describing small populations of individuals which could not be proved to reflect the prevalence of a given area, region or country were excluded. Only studies describing adolescent or adult populations were included. Reference lists of relevant articles were screened for further potential studies and citation searches were conducted. Only studies describing transsexualism as per Benjamin ${ }^{(12)}, \operatorname{ICD}^{(1,9)}$ or $\operatorname{DSM}^{(2,3,7,10,11)}$ definitions were selected. Table 1 details the criteria for search used for this review.

Table 1 insert around here

When the study did not describe some of the above information, whenever possible, this was calculated by the authors. For example, in some cases the mean population of the studied area was calculated. Studies were excluded where there was ambiguity in the number of individuals with a clear diagnosis or studies that primarily included individuals who were self-diagnosed or had not been diagnosed by a professional ${ }^{(19}$, 28).

\subsection{Procedure}

Studies meeting the inclusion criteria were examined. The study collected the available information for the following outcomes of interest: 1) prevalence of transsexual individuals in general per 100,000 individuals; 2) prevalence of trans women per 100,000 individuals; 3 ) prevalence of trans men per 100,000 individuals; 4) sex ratio between males and females; 5) country or region where the study took place; 6) number of years during which information was collected; 7) information 
regarding methods used to identify trans individuals; and 8) the change in the trans men/trans women ratio as a function of time (descriptive information).

\subsection{Included and excluded studies}

Studies were screened in three phases, namely title, abstract, and full text. In the first instance the titles were screened $(n=1724)$. The number of studies found using the above search terms were: Transgender (TG) plus epidemiology (259), TG plus incidence (28) and TG plus prevalence (257). Transsexualism (TS) plus epidemiology (143), TS plus incidence (51) and TS plus prevalence (130); Gender dysphoria (GD) plus epidemiology (24), GD plus incidence (4), GD plus prevalence (11); Gender identity disorder (GID) plus epidemiology (390), GID plus incidence (41) and GID plus prevalence (384). Gender non conforming (GNC) plus epidemiology (1), GNC plus incidence (0) and GNC plus prevalence (1). Duplicates were removed ( $\mathrm{n}=251)$, and the two independent reviewers (JA and GW) independently screened and coded the remaining titles $(n=1473)$. Based on the titles, 1223 papers were excluded. The main reason for exclusion was that the studies did not describe prevalence of Transsexualism, Gender Identity Disorder or Gender Dysphoria, but prevalence of other disorders such as mental health problems or HIV in trans individuals. Out of the 250 studies selected to be screened in detail, 211 were excluded after reading the abstracts. The reasons for the exclusions were: inadequate sample size (case studies); 2) no prevalence data; and 3) no specific area, region or country covered by the study. Out of the 39 papers retrieved for more detailed evaluation, five were excluded as there was no exact epidemiological information or they were not covering a specific, identifiable area (these were not excluded in the previous stage as this information was not identifiable by reading the abstract). Four more studies were excluded as they 
only described the prevalence of psychiatric co-morbidity, and a further five studies were excluded as the population was self-identified or it was unclear as to whether the participants fulfilled diagnostic criteria. In addition, a case study, a general review on the etiology of transsexualism (with no new data), and two studies that described only children were also excluded. In total 21 studies were systematically reviewed.

\section{Insert figure 1 around here}

\subsection{Assessment of quality}

The study used a checklist for cross sectional studies based on the NICE checklists ${ }^{(29)}$ developed by Gilbert ${ }^{(30)}$ and used in previous studies ${ }^{(31)}$. The NICE rating system rates the studies from good quality (when all or most of the criteria have been fulfilled; $[++]$ ), reasonable quality (when some of the criteria have been fulfilled; $[+]$ ), to poor quality (when few or no criteria are fulfilled; [-]). The review and scoring was based on the quality of the study reporting prevalence of transsexualism. Some of the studies were qualitatively excellent but reported prevalence of sex reassignment surgery instead of transsexualism. In these cases, studies were scored as $+*$ to indicate this.

\section{5. Statistical analysis}

To calculate the meta-analytical prevalence, only studies that reported new data were included. When several studies used the same data but at different times (i.e., data from clinical databases across years), only the newest point prevalence data was selected. In contrast, to calculate time series analysis, information from studies describing period prevalence were included and the mean year of the studied period 
was used as a moderator for the analysis. For studies that spanned several years, the total number of cases (trans men, trans women) were divided by the number of years covered by the study in order to calculate the prevalence per year. Any missing information was estimated.

The primary data of the epidemiological studies were extracted as raw numbers. An aggregate effect size, weighted by sample size, was computed to provide an overall effect size across the studies. Homogeneity among studies was computed using the Q statistic and the $I^{2}$ statistic. A significant Q statistic suggests that the distribution of effect size around the mean is greater than would be predicted from sampling error alone, whereas $I^{2}$ provides an estimate of the proportion of the variance in the aggregate effect size that is attributable to between-studies heterogeneity ${ }^{(32)}$. Randomeffects models were fitted if there was heterogeneity. Risk ratios and 95\% confidence intervals (CIs) were calculated. The relative weighted contribution of each study was also assessed. Meta-analysis was performed using the Comprehensive Meta-Analysis software programme-2 for Windows ${ }^{(33)}$ according to the Cochrane reviewers' handbook $^{(34)}$. Significance was set at $p<0.05$.

\section{Results}

\subsection{Study characteristics}

Most of the studies published were from Europe (18; 85.7\%): five from Sweden ${ }^{(17,22,}$ $35,36,37)$, three from the Netherlands ${ }^{(18,38,39)}$, three from the United Kingdom ${ }^{(40,41,42)}$, two from Germany ${ }^{(13,43)}$ and one each from $\operatorname{Spain}^{(44)}$ Belgium $^{(45)}$ Serbia $^{(46)}$, Ireland $^{(47)}$, and Poland ${ }^{(48)}$. There was only one study from the United States of America (USA), which was also the oldest ${ }^{(16)}$, only one from Singapore ${ }^{(23)}$, and only 
one from Australia ${ }^{(49)}$. Most of the studies from the same country, such as the Dutch and the Swedish studies, used the same data but at different periods therefore covering different years. Other studies from the same country focused on different areas, regions or counties within the country, such as East and West Germany, and Northern Ireland, Scotland or England (three from the United Kingdom). The study period varied from three years ${ }^{(22)}$ to an impressive 50 years $^{(17)}$.

Employing the NICE rating system described above, there were four studies that were scored as (-). This was because they were particularly old studies reporting epidemiological data calculated from approximations ${ }^{(16)}$, or from information collected from third parties (such as psychiatrists via questionnaires ${ }^{(50)}$, or from primary care $\left.{ }^{(42)}\right)$. They were also rated as (-) if the information regarding how individuals could access the gender clinic and whether the clinic covered a specific geographical area was unclear ${ }^{(48)}$. Six studies scored $(+)$ as although methodologically strong, the information was gathered from third parties (courts or government ${ }^{(28,43)}$, endocrinologists $^{(47)}$ or surgeons $\left.{ }^{(45)}\right)$, or the geographical area covered was unclear ${ }^{(40 \text {, }}$ 41). Two studies that focused specifically on sex reassignment surgery were scored as $(+*)^{(17,46)}$. The rest of the studies scored $(++)$ as they were methodologically strong and provided clear epidemiological information regarding the prevalence of transsexualism in the specific country, based on individuals attending a gender identity clinic. Most of the studies were from the same countries, such as the Netherlands and Sweden.

\subsection{Population studied}


All of the 21 studies selected for the systematic review defined the population studied as transsexual individuals. The majority of the studies used data gathered retrospectively from gender identity clinics. The clinics covered the whole of their countries, such as the Netherlands ${ }^{(18)}$, or a specific geographical area within the country, such as Catalonya in Spain ${ }^{(44)}$. The studies used the $\operatorname{ICD}^{(1)}, \mathrm{DSM}^{(2,3)}$ or Benjamin's ${ }^{(12)}$ criteria to define the population.

The reviewed studies provided reliable data and identified a population of transsexual individuals in the following way: seven studies described individuals referred to a gender identity clinic (who fulfilled diagnostic criteria), four studies described individuals who were treated with cross-sex hormones who fulfilled the diagnosis, five studies described individuals who had or were referred for sex reassignment surgery (SRS) and five studies collected information regarding the possible number of transsexual individuals by accessing Governmental organizations, i.e. the bureau of records or virtual statistics. In spite of the complication of reaching a clear diagnosis, most studies were able to provide the estimate of the number of transsexual individuals, trans men and trans women from the age of 15 years.

\subsection{Prevalence of transsexualism}

Out of the 21 studies selected, 20 provided information on the number of transsexual individuals in their study and gave information about the population that the clinic or studied area covered. The American study ${ }^{(16)}$ provided only an approximation of trans individuals. Although it is historically important, it does not provide enough information for analysis. As explained above, studies using the same database, but at different time periods were removed for this analysis and only the most recent ones 
selected. Therefore out of the 20 studies, 12 provided enough new data on prevalence. Those studies provided point prevalence as they reported the number of transsexual individuals at the point when the study took place by reporting the number of individuals since the clinic opened or records began. The prevalence of trans individuals was studied in 12 countries with a total population of 95,141,541 individuals. The largest population studied was in West Germany with nearly 35 million individuals included ${ }^{(43)}$. There was a similar group of natal males and females within the overall general population with 30,651,864 males and 31,689,246 females.

The 12 studies identified a total of 4355 trans individuals. The largest number of trans individuals were identified in the German study that looked at gender identity clinics in specific areas of Germany, with a total of 1773 trans individuals ${ }^{(13)}$. However, this study did not provide the highest prevalence of transsexual individuals per 100,000 people. Rather, this was reported in the Singaporean study (23.60 Singapore-born trans individuals per 100,000 people ${ }^{(23)}$. This study may underestimate the total number of trans individuals in Singapore, as it only includes those who go for sexreassignment surgery, which is only a proportion of all trans people. Not unexpectedly, more recent studies found higher prevalence rates than older studies. As an example, the recent Swedish study found a prevalence of 16.67 per $100,000^{(17)}$.

Meta-analysis found an overall prevalence of transsexualism using random effects meta-analysis of $0.000046(95 \% \mathrm{CI}=0.000028-0.000077)$. Heterogeneity was high $\left(\mathrm{I}^{2}\right.$ $=99.6 \%$; $\mathrm{Q}$ value $=3314.7)$ therefore the random effect was selected. This indicates a prevalence of transsexualism of 4.6 per 100,000 or 1 in every 21,739 individuals. 
Insert table 2 around here

\subsection{Prevalence of trans women}

All studies identified a higher prevalence of trans women compared to trans men, with the exception of the study by Godlewski( ${ }^{(48)}$ with a score of (-). Prevalence rates of trans women varied between $0.44^{(22)}$ and 35.2 per $100,000^{(23)}$.

As one of the studies did not report the number of female or male individuals in the population studied, this study was removed from subsequent analysis ${ }^{(43)}$. Therefore, eleven studies were included in the meta-analysis. An overall prevalence rate of $0.000068(95 \% \mathrm{CI}=0.00004-0.00010)$ of trans women was found. Heterogeneity was high $\left(I^{2}=99.0 \%\right.$; Q value $\left.=1070.35\right)$ therefore random effect was selected. This indicates a prevalence of trans women of 6.8 per 100,000 or 1 in every 14,705 individuals.

\section{Insert Table 3 around here}

\subsection{Prevalence of trans men}

Most studies reported a smaller number of trans men when compared to trans women. Prevalence rates varied from $0.25^{(16)}$ to 6.64 per $100,000^{(17)}$. The trans women to trans men ratios varied from 6.1 trans women to every one trans men $(6: 1)^{(49)}$ to 1 to 1 $(1: 1)^{(46)}$.

Eleven studies were included in the meta-analysis. An overall prevalence rate of $0.000026(95 \% \mathrm{CI}=0.000017-0.00004)$ was found. Heterogeneity was also high $\left(\mathrm{I}^{2}\right.$ 
$=97.7 \%$; $\mathrm{Q}$ value $=435.1$ ). This indicates a prevalence of trans men of 2.6 per 100,000 or 1 in every 38,461 individuals. Using meta-analytical prevalence rates, the ratio of trans women to trans men was found to be 2.6 trans women for every trans man $(2.6: 1)$.

Insert table 4 around here

Insert table 5 around here

\subsection{Change of prevalence rates over the years}

For the time series analysis 17 studies that provided period prevalence data at different time points were included. Most of the studies provided data from a period of time between 4 and 10 years. In order to undertake time series analysis a regression analysis was undertaken with date as a moderator variable. The date selected was calculated as the mean of the numbers of years of the study period. Time series analysis showed a statistically significant effect for general transsexualism $(z=23.45$, $p<0.001)$, trans women $(\mathrm{z}=22.13, p<0.001)$, and trans men $(z=8.00, p<0.001)$ suggesting a higher prevalence of transsexual individuals, trans women and trans men in more recent studies.

Insert figure 2 around here

\section{Discussion}

This is the first study that has aimed to critically review and meta-analytically investigate the prevalence of transsexualism. Twenty-one studies were identified as 
having enough data and using similar diagnostic criteria suitable for a critical review, with 12 studies having enough data to perform a meta-analysis. Most epidemiological studies in this area have investigated the prevalence rates of HIV in this population $^{(51,52,53)}$ and very few have investigated the number of trans people in the general population, which may be due to the complex methodology required to undertake such studies.

This study showed that there has been a clear increase in the prevalence of individuals diagnosed with transsexualism over time, with newer studies reporting statistically significant higher rates than older studies. Countries using the same database over the years have reported an increased prevalence of individuals attending clinical services, receiving prescribed cross-sex hormones, or applying for sex reassignment surgery. The overall meta-analytical prevalence of transsexualism was found to be 4.6 per 100,000 , with the meta-analytical prevalence of trans women being higher ( 6.8 in $100,000)$ than that of trans men $(2.6$ in 100,000$)$. Although the sex ratio has moved closer to $1: 1$, using the meta-analytical prevalence, the trans women to trans men ratio was calculated to be 2.6 to 1 .

The increase in prevalence over the years is likely due to several factors: the increased visibility of trans people in the media, which likely contributes to at least a partial destigmatization of being trans ${ }^{(54)}$; the wide availability of information on the Internet about transsexualism or Gender Dysphoria, which also likely contributes to destigmatization $^{(54)}$; the increased awareness of the availability of biomedical treatment ${ }^{(4,5,20)}$; and the development of societal tolerance towards trans individuals $^{(15)}$. With regards to the latter, most of the studies investigating social attitudes to gender and sexual diversity have primarily explored peoples' attitudes 
towards gay, lesbian, and bisexual (LGB) individuals. The 2012 edition of the Eurobarometer however, included questions aiming at measuring the public attitudes to transgender people in European countries for the first time. The most tolerant countries appear to be Denmark, Luxembourg, Ireland, Sweden and the United Kingdom. Interestingly, the proportion of individuals who feel uncomfortable with trans people was larger than for LGB people in all European countries. In six European countries the majority of people report to feel comfortable with a trans person as a government leader: Denmark, Sweden, Luxembourg, Spain, the United Kingdom and the Netherlands ${ }^{(15)}$. This report is the first to specifically explore societal tolerance towards trans people.

Recent reports indicate that the number of individuals with gender dysphoria who attend clinical services for an assessment has increased substantially over the years in many European countries ${ }^{(54,55)}$. There is also a significant increase in people who self-diagnose as suffering from gender dysphoria ${ }^{(19)}$. Although this review did not include studies of people who self-diagnose, such studies are important as they may indicate the level of future demand for clinical services. For example Kuyper and Wijsen $^{(19)}$ found that $4.6 \%$ of natal men and $3.2 \%$ of natal women in their Dutch population sample reported an ambivalent gender identity (equal identification with other sex as with sex assigned at birth) and $1.1 \%$ of the natal men and $0.8 \%$ of the natal women reported an incongruent gender identity (stronger identification with other sex as with sex assigned at birth). It remains unknown how many of their sample will seek assessment and treatment via a gender identity clinic service.

Many trans individuals require clinical services as they wish to have cross-sex hormone treatment and surgery to alleviate their gender dysphoria. However, some 
feel that only one of these treatment modalities is necessary for them, whilst others may decide to not take cross-sex hormones or undergo any operations ${ }^{(56,57)}$. Psychotherapy can be helpful for some individuals to integrate their transgender feelings into their gender role assigned at birth and do not feel the need to feminize or masculinize their body; for those changes in social gender role and expression can be sufficient to alleviate gender dysphoria ${ }^{(20,57)}$. Moreover, many trans individuals may have socially transitioned with or without partial treatment through self-prescribed cross sex hormones or private means ${ }^{(58,59)}$.

The complex care pathway of trans individuals, makes the organization of service delivery difficult to plan ahead. The prevalence of people requiring assessment and treatment for gender dysphoria may be more accurately estimated by looking at community studies. Studies reporting prevalence rates of SRS are likely to underestimate the true prevalence of transsexualism in the community. Since one of the largest studies in this meta-analysis identified their participants via applications for SRS ${ }^{(21)}$, the overall prevalence rate is likely to be higher than the one reported in this meta-analysis.

The main strength of this paper is the fact that this is the first study that summarizes and critically assesses all the available data in the subject of trans epidemiology taking into consideration the weight of the study in the analysis, in order to avoid biased results based on large studies. While studies have become methodologically stronger over the years, this review and meta-analysis is limited by the available data. The majority of the studies were conducted in Western countries, particularly in Europe, and the results may be related to the level of tolerance of society, the 
healthcare system available, legislation regarding the rights of trans people and the academic interest in the area of trans healthcare. This is clearly reflected by the large body of research originating from Europe, particularly in Sweden and the Netherlands. There are a limited number of reports regarding trans individuals from developing countries ${ }^{(60,61,62,63)}$.This may simply indicate that while trans individuals do indeed have access to services, no epidemiological studies have been undertaken. Alternatively, for some countries it may indicate that there are no clinical services available and that trans individuals in these areas need to suppress their real self, the consequence of which may be the development of mental health problems ${ }^{(64,65,66)}$.

The study is limited by the high heterogeneity of the included studies, which is not surprising as there are clear differences between the methodology of the studies included in the review. This is reflected in the great variation of prevalence data from the different studies. We use a random effects model in an effort to incorporate heterogeneity between the studies in our analysis but recognize that this does not eliminate the fact that heterogeneity was present. In spite of the limitations of this meta-analytical study, and the majority of the prevalence studies reviewed, the existing data should be considered as a starting point. The field would benefit from more rigorous epidemiological studies acknowledging current changes in classification system and including different locations worldwide. 


\section{References}

1. World Health Organization. International Classification of Diseases 10 (ICD-10). Geneva: World Health Organization.1992.

2. American Psychiatric Association. Diagnostic and Statistical Manual of Mental Disorders (DSM3), 3rd ed. Washington, DC: American Psychiatric Press. 1980.

3. American Psychiatric Association. Diagnostic and Statistical Manual of Mental Disorders, (DSM-III-R), Revised 3rd ed. Washington, DC: American Psychiatric Press. 1987.

4. Ahmad S, Barrett J, Beaini AY, et al. Gender dysphoria services: a guide for general practitioners and other healthcare staff. Sex Relat Ther. 2013;28(3):173-186. doi:10.1080/14681994.2013.808884

5. Wylie K, Barrett J, Besser M, et al. Good Practice Guidelines for the Assessment and Treatment of Adults with Gender Dysphoria. Sex Relat Ther. 2014;29(2):154-214. doi:10.1080/14681994.2014.883353

6. Drescher J, Cohen-Kettenis P, Winter S. Minding the body: situating gender identity diagnoses in the ICD-11. Int Rev Psychiatr. 2012;24:568-77. doi:10.3109/09540261.2012.741575

7. American Psychiatric Association. Diagnostic and Statistical Manual of Mental Disorders (DSM5), 5th ed. Washington, DC: American Psychiatric Press. 2013.

8. Gerstman B. Epidemiology Kept Simple: An Introduction to Traditional and Modern Epidemiology, 2nd ed. Hoboken, NJ: Wiley-Liss. 2003. Retrieved from http://eu.wiley.com/WileyCDA/WileyTitle/productCd-0471400289.html on 11th January 2015.

9. World Health Organization. International Classification of Diseases 9 (ICD-9). Geneva: World Health Organization. 1978.

10. American Psychiatric Association. Diagnostic and Statistical Manual of Mental Disorders (DSM4), 4th ed. Washington, DC: American Psychiatric Press. 1994. 
11. American Psychiatric Association. Diagnostic and Statistical Manual of Mental Disorders (DSM4R), Revised 4th ed. Washington, DC: American Psychiatric Press. 2000.

12. Benjamin H. The transsexual phenomenon. New York: The Julian Press.1966.

13. Garrels L, Kockott G, Michael N, et al. Sex ratio of transsexuals in Germany: the development over three decades. Acta Psychiat Scand. 2000;102(6):445-448.

14. FRA. Being trans in the European Union: Comparative analysis of the EU LBGT survey data. Vienna. FRA - European Union Agency for Fundamental Rights. 2014.

15. Keuzenkamp S, Kuyper L. Acceptance of LGBT individuals in the Netherlands 2013. The Hague. The Netherlands Institute of Social Research (ED). 2013.

16. Pauly IB. The current status of the change of sex operation. J Nerv Ment Dis. 1968;147(5):460-471.

17. Dhejne C, Oberg K, Arver S, Landén M. An Analysis of All Applications for Sex Reassignment Surgery in Sweden, 1960-2010: Prevalence, Incidence, and Regrets. Arch Sex Behav. 2014:43(8):1535 - 1545. doi:10.1007/s10508-0140300-8

18. Eklund P, Gooren L, Bezemer P. The prevalence of transsexualism in The Netherlands. Brit J Psychiat. 1988;152:638-640. doi:10.1192/bjp.152.5.638

19. Kuyper L, Wijsen C. Gender identities and gender dysphoria in the Netherlands. Arch Sex Behav. 2014:43(2):377-385. doi:10.1007/s10508-013-0140-y

20. Coleman E, Bockting W, Botzer M, et al. Standards of Care for the Health of Transsexual, Transgender, and Gender-Nonconforming People, Version 7. Int J Transgen. 2012;13(4):165-232. doi:10.1080/15532739.2011.700873

21. Zucker KJ, Lawrence AA. Epidemiology of Gender Identity Disorder: Recommendations for the Standards of Care of the World Professional Association for Transgender Health. Int J Transgen. 2009:11:8-18. doi:10.1080/15532730902799946

22. Wålinder J. Incidence and sex ratio of transsexualism in Sweden. Brit J Psychiat. 1971;119:195-196. doi:10.1192/bjp.119.549.195 
23. Tsoi W. The prevalence of transsexualism in Singapore. Acta Psychiat Scand. 1988;78:501-504.

24. Nanda, S. The Hijras of India: cultural and individual dimensions of an institutionalized third gender role. J Homosex. 1985;11:35-54.

25. Nanda, S. Neither Man nor Woman. The Hijras of India. Second edition. Belmont, USA: Wadsworth. 1998.

26. Reddy, G. With respect to sex. Chicago, USA: University of Chicago. 2005.

27. Moher D, Liberati A, Tetzlaff J, Altman DG, The PRISMA Group. Preferred reporting items for systematic reviews and meta-analyses: The PRISMA Statement. PLoS Med. 2009;6, e1000097. DOI: 10.1371/journal.pmed.1000097

28. Veale JF. Prevalence of transsexualism among New Zealand passport holders. Aust NZ J Psychiat. 2008;42(10):887-889. doi:10.1080/00048670802345490

29. National Institute of Health and Clinical Excellence. The Guidelines Manual. London: National Institute for Clinical Excellence. 2007. Retrieved online from www.nice.org.uk on $11^{\text {th }}$ January 2015.

30. Gilbert N. Disclosure of eating disorders and subsequent help seeking. Unpublished thesis. 2009. Birmingham University, UK. Retrieved online from http://etheses.bham.ac.uk/428/ on $11^{\text {th }}$ January 2015.

31. Arcelus J, Haslam M, Farrow C, Meyer C. The role of interpersonal functioning in the maintenance of eating psychopathology: A systematic review and testable model. Clin Psychol Rev. 2013;33(1):156-167. doi: 10.1016/j.cpr.2012.10.009

32. Higgins JPT, Thompson SG. Quantifying heterogeneity in a meta-analysis. Stat Med. 2002;21(11):1539-58. doi:10.1002/sim.1186

33. Borenstein M, Hedges L, Higgins J, Rothstein H. Comprehensive meta-analysis. Version 2. Englewood NJ: Biostat. 2005.

34. Higgins JP, Green S. Cochrane handbook for systematic reviews of interventions Version 5.1.0. 2011. Retrieved online from www.cochrane-handbook.org on $11^{\text {th }}$ January 2015. 
35. Landén M, Wålinder J, Hambert G, Lundström B. Factors predictive of regret in sex reassignment. Acta Psychiat Scand. 1998;97(4):284-289.

36. Olsson SE, Moller AR. On the Incidence and Sex Ratio of Transsexualism in Sweden, 1972-2002. Arch Sex Beh. 2003;32(4):381-386. doi: 10.1023/A:1024051201160

37. Wålinder J. Transsexualism: A study of fourty-three cases. Goteborg: Scandinavian University Books.1967.

38. Bakker A, Van Kesteren PJM, Gooren L, Bezemer P. The prevalence of transsexualism in the Netherlands. Acta Psychiat Scand. 1993;87:237-238.

39. Van Kesteren PJ, Gooren LJ, Megens JA.An epidemiological and demographic study of transsexuals in the Netherlands. Acta Psychiat Scand. 1996; 87(4):237-238.

40. Hoenig J, Kenna JC. The prevalence of transsexualism in England and Wales. Brit J Psychiat. 1974;124(579):181-190. doi:10.1192/bjp.124.2.181

41. O'Gorman EC. A preliminary report on transsexualism in Northern Ireland. Ulster Med J. 1981;50(1):46-49.

42. Wilson P, Sharp C, Carr S. The prevalence of gender dysphoria in Scotland: a primary care study. Brit J Gen Pract. 1999;49(449):991-992.

43. Weitze C, Osburg S. Transsexualism in Germany: empirical data on epidemiology and application of the German Transsexuals' Act during its first ten years. Arch Sex Behav. 1996;25(4):409-425.

44. Gómez-Gil E, Trilla Garcia A, Godas Sieso T, et al. Estimacion de la prevalencia, incidencia y razon de sexos del transexualismo en catalunya segun la demanda asistencial. Acta Espan Psychiat. 2006;34(5):295-302.

45. De Cuypere G, Van Hemelrijck M, Michel A, et al. Prevalence and demography of transsexualism in Belgium. Eur Psychiat. 2007;22(3):137-141. doi:10.1016/j.eurpsy.2006.10.002

46. Vujovic S, Popovic S, Sbutega-Milosevic G, Djordjevic M, Gooren LJ. Transsexualism in Serbia: A twenty-year follow-up study. J Sex Med. 2009;6(4):1018-1023. doi: 10.1111/j.1743-6109.2008.00799.x 
47. Judge C, O’Donovan C, Callaghan G, Gaoatswe G, O'Shea D. Gender dysphoria prevalence and co-morbidities in an Irish adult population. Front Endocrinol. 2014;5:87. doi:10.3389/fendo.2014.00087

48. Godlewski J. Transsexualism and anatomic sex ratio reversal in Poland. Arch Sex Behav. 1988;17(6):547-548.

49. Ross M, Wålinder J, Lundstrom B, Thuwe I. Cross-cultural approaches to transsexualism. Acta Psychiat Scand. 1981;63:75-83.

50. Wålinder J. Transsexualism: definition, prevalence and sex distribution. Acta Psychiat Scand. 1968;203:255-257.

51. Operario D, Soma T, Underhill K. Sex work and HIV status among transgender women: Systematic review and meta-analysis. JAIDS 2008; 48:97-103.

52. Nuttbrock L, Bockting W, Rosenblum A, et al. Gender abuse, depressive symptoms, and HIV and other sexually transmitted infections among male-tofemale transgender persons: a three-year prospective study. Am J Public Health 2013; 103:300-307.

53. Poteat T, Reisner SL, Radix A. HIV epidemics among transgender women. Curr Opin HIV AIDS 2014; 9: 168-173.

54. Aitken M, Steensma TD, Blanchard R, VanderLaan DP, Wood H, Fuentes A, Spegg C, Wasserman L, Ames M, Lindsay Fitzsimmons C, Leef JH, Lishak V, Reim E, Takagi A, Vinik J, Wreford J, Cohen-Kettenis PT, de Vries ALC, Kreukels BPC, Zucker KJ. Evidence for an altered sex ratio in clinic-referred adolescents with gender dysphoria. J Sex Med. 2015;12: 756-763.

Doi:10.1111/jsm.12817

55. de Vries ALC, Kreukels BPC, T’Sjoen G, Ålgars M, Mattila A. Increase of referrals to gender identity clinics: A European trend? In: Transgender Healthcare in Europe. Book of Abstract. pp10. Ghent, Belgium: European Professional Association of Transgender Health (EPATH). 2015. Retrieved online from http://epath.eu/wp-content/uploads/2014/07/EPATH2015-Book-of-Abstracts.pdf on 8th April 2015.

56. Bockting W, Coleman E, De Cuypere G. Care of transsexual persons. New Engl J Med. 2011;364:2259-2560. doi:10.1056/NEJMc1104884 
57. Bockting WO. Psychotherapy and the real-life experience: From gender dichotomy to gender diversity. Sexologies. 2008;17:211-224. doi:10.1016/j.sexol.2008.08.001

58. Davies A, Bouman WP, Richards C, et al. Patient satisfaction with gender identity clinic services in the United Kingdom. Sex Relat Ther. 2013;28(4):400-418. doi:10.1080/14681994.2013.834321

59. Mepham NL, Bouman WP, Arcelus J, Wylie KR, Hayter M. People with Gender Dysphoria who self prescribe cross sex hormones: Prevalence, sources and side effects knowledge. J Sex Med. 2014;11: 2995-3001. doi:

10.1111/jsm. 1269

60. Franz RC. Sigmoid colon vaginoplasty: A modified method. Brit J Obstet Gynaec. 1996;103:1148-1155.

61. Ruan FF, Bullough VL, Tsai YM. Male transsexualism in mainland China. Arch Sex Behav. 1989;18:517-522.

62. Zhaoji X, Chuanmin W, Bullough VL. Transsexualism in China in 1995. In B. Bullough, V. L. Bullough, \& J. Elias (Eds.), Gender blending (pp. 377-382). Amherst, NY: Prometheus Books. 1997.

63. Hahn T. Jin Xing, a dancer and leader of the Xing Dance Theatre in Shanghai, China, and a transsexual. Ballettanz. 2004;3:22-25.

64. Claes L, Bouman WP, Witcomb G, Thurston M, Fernandez-Aranda F, Arcelus J. Non-Suicidal Self-Injury in Trans People: Associations with Psychological Symptoms, Victimization, Interpersonal Functioning and Perceived Social Support. J Sex Med. 2014. doi: 10.1111/JSM.12711

65. Davey A, Bouman WP, Arcelus J, Meyer C. Social support and psychological wellbeing: A comparison of patients with gender dysphoria and matched controls. J Sex Med. 2014;11(12):2976-2985. doi: 10.1111/jsm.12681

66. Heylens G, Elaut E, Kreukels BPC, et al. Psychiatric characteristics in transsexual individuals: multicentre study in four European countries. Brit J Psychiat: J Ment Sci. 2013;204(2):151-156. doi:10.1192/bjp.bp.112.121954 

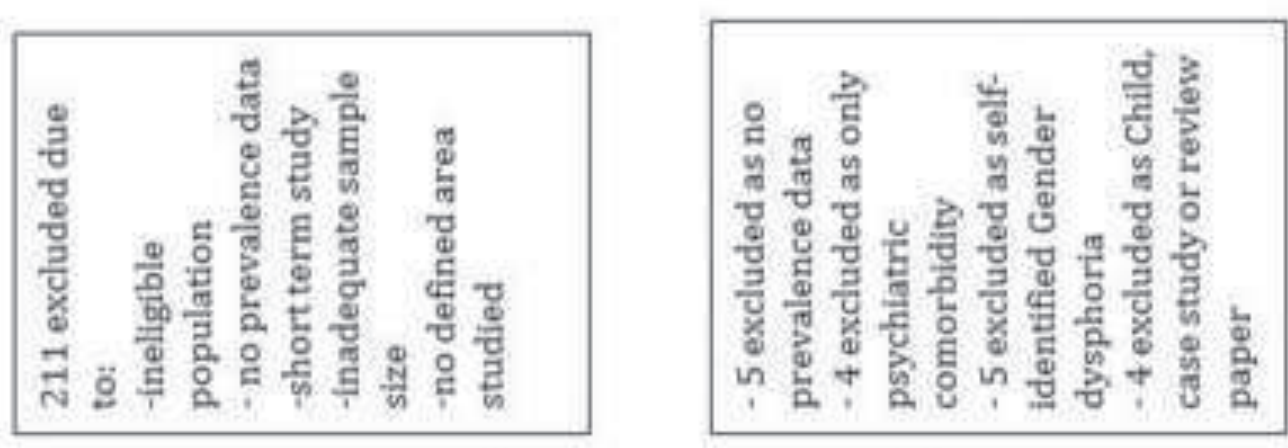

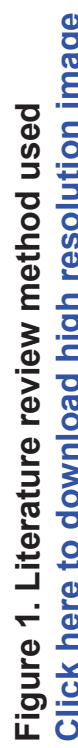
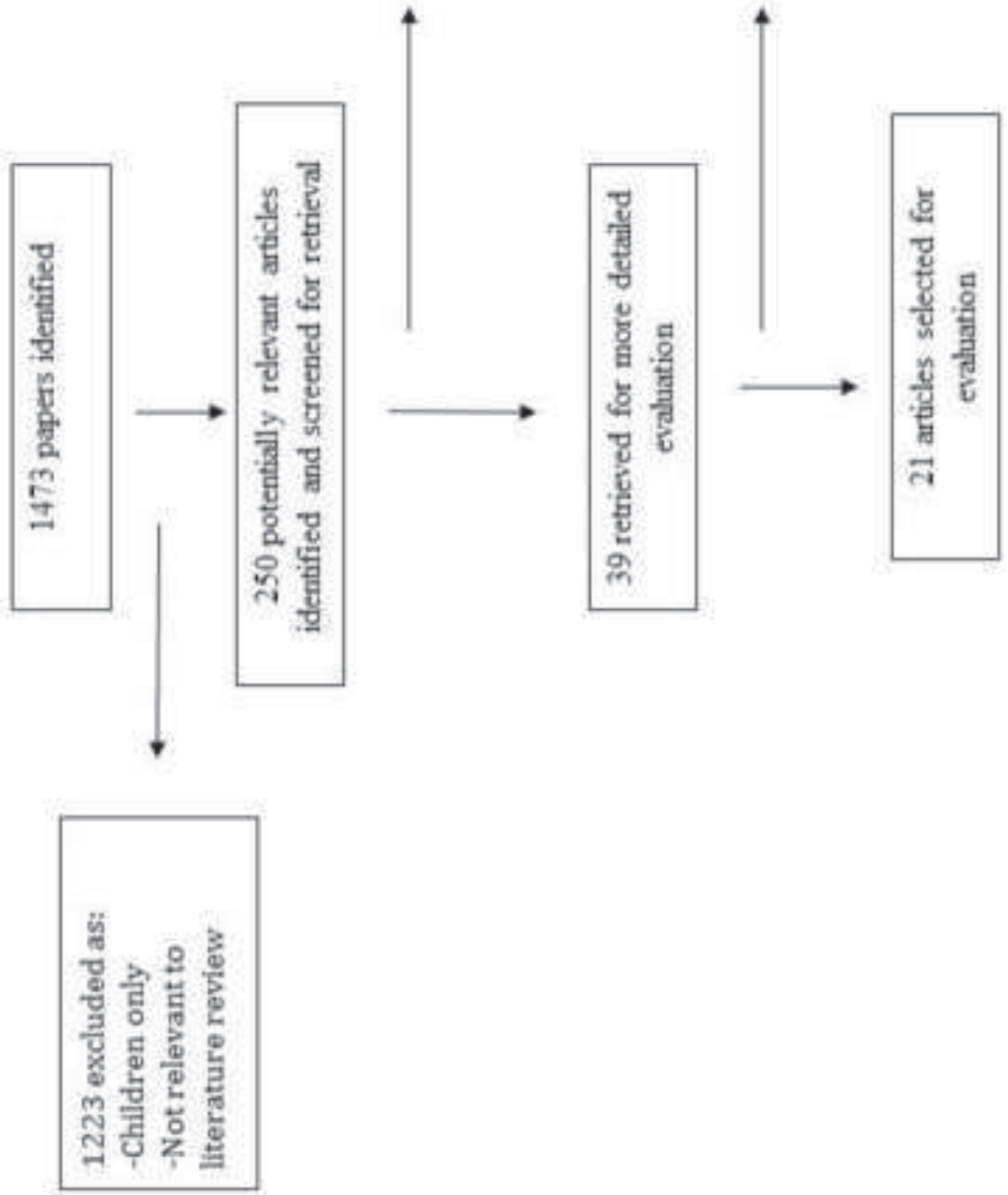


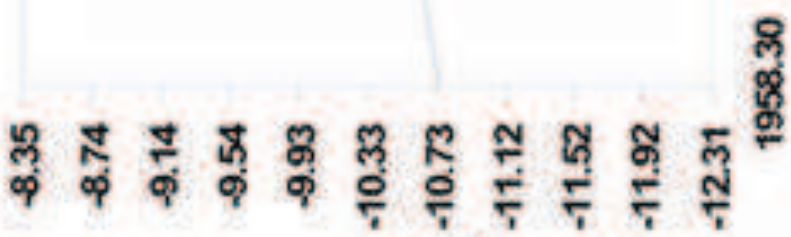

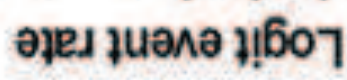


Table 1: Criteria for searches on prevalence of Transsexualism

\begin{tabular}{|c|c|}
\hline Category & Criteria \\
\hline Study population & $\begin{array}{l}\text { All races, ethnicities, and cultural groups } \\
\text { Adults ( }>18 \text { years) or adolescents (18-15 } \\
\text { years); no children ( }<15 \text { years })\end{array}$ \\
\hline Study settings and geography & All nations \\
\hline Time period & Published from 1954 through June 2014 \\
\hline Publication criteria & $\begin{array}{l}\text { Included: } \\
\text { - All languages } \\
\text { - Articles in print or online } \\
\text { Excluded: } \\
\text { - Articles in grey literature or non-peer- } \\
\text { reviewed journals or unobtainable during } \\
\text { the review period }\end{array}$ \\
\hline $\begin{array}{l}\text { Admissible evidence } \\
\text { (Study design and } \\
\text { other criteria) }\end{array}$ & $\begin{array}{l}\text { Transsexualism, Gender Identity Disorder } \\
\text { or Gender Dysphoria must be diagnosed } \\
\text { according to DSM III, DSM III-R, DSM } \\
\text { IV, DSM-IV-TR, DSM-V, ICD-9, ICD-10, } \\
\text { or Benjamin criteria. } \\
\text { Prevalence must be available or be able to } \\
\text { be extracted from the data. } \\
\text { Country, number of years used to extract } \\
\text { the data, number of trans individuals, natal } \\
\text { or preferred gender, mean age, general } \\
\text { population of the studied area (divided by } \\
\text { natal males and female), to be recorded } \\
\text { when possible. }\end{array}$ \\
\hline & Eligible study designs include: \\
\hline
\end{tabular}




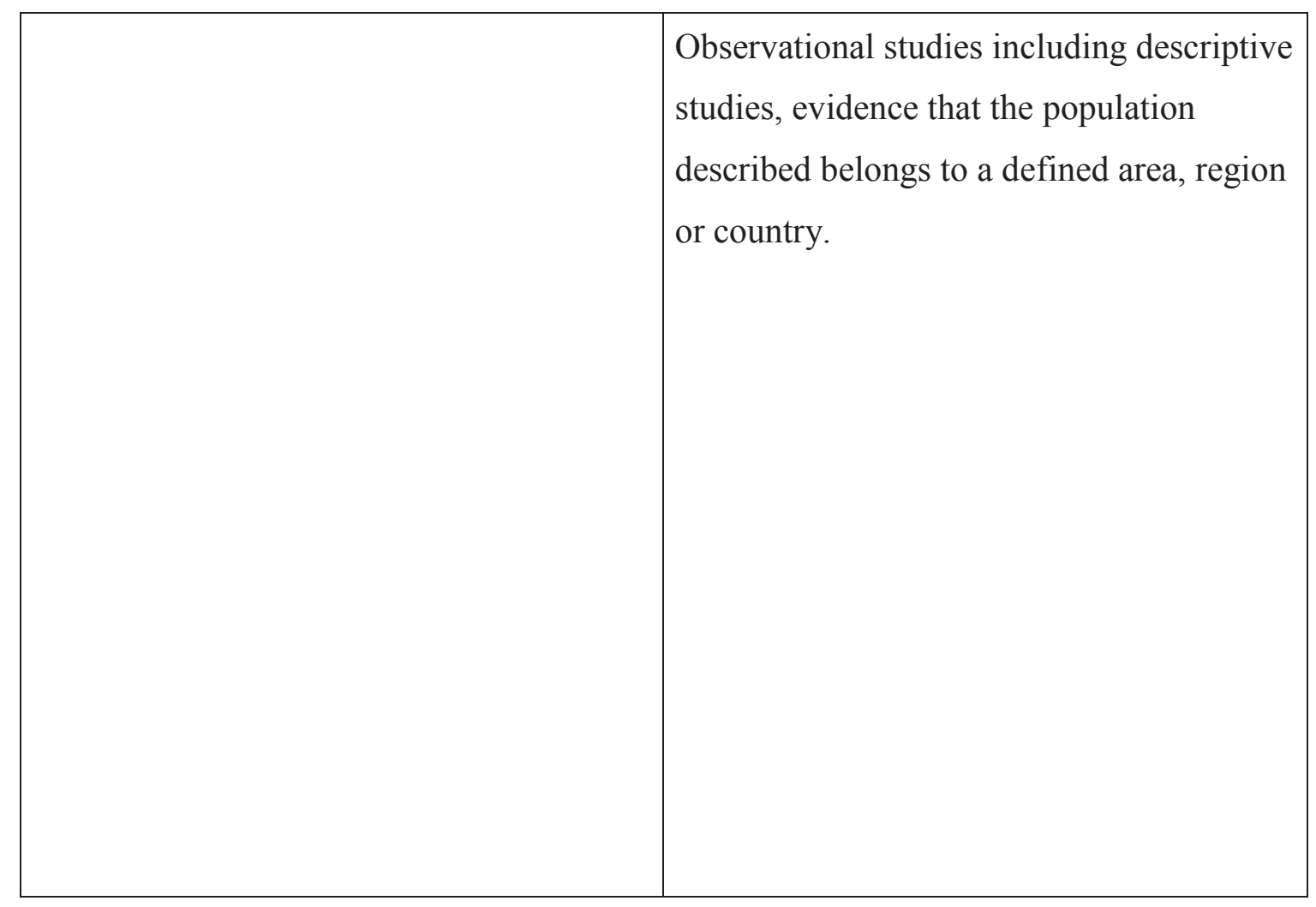




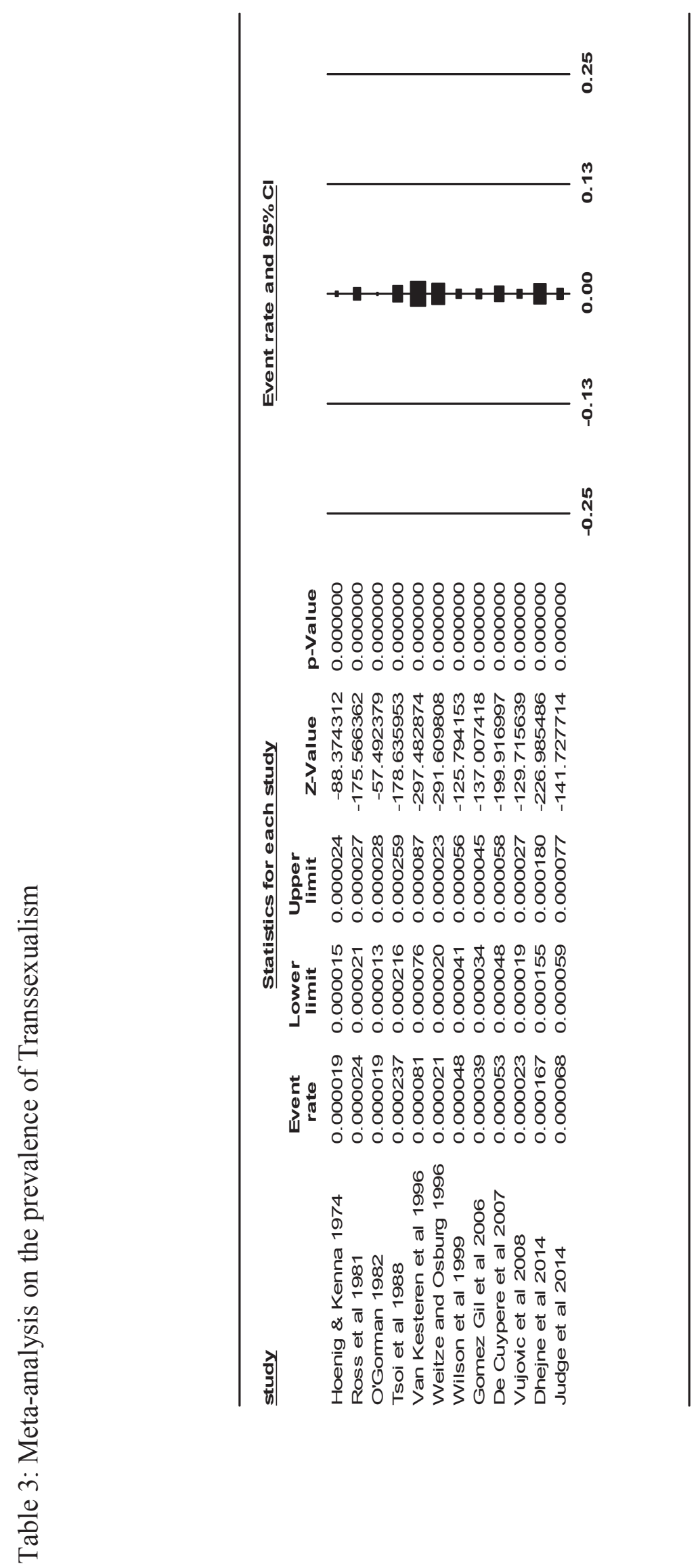





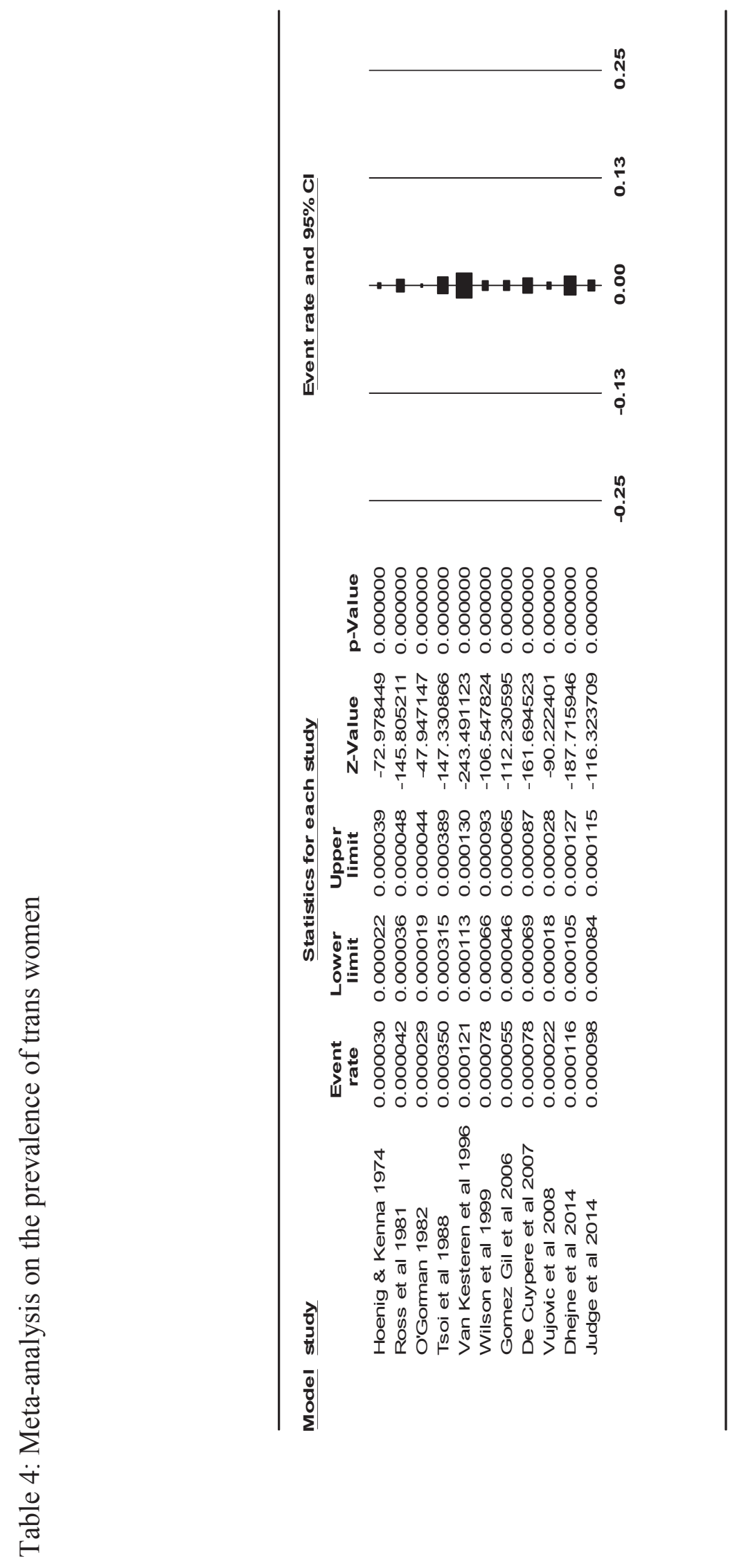




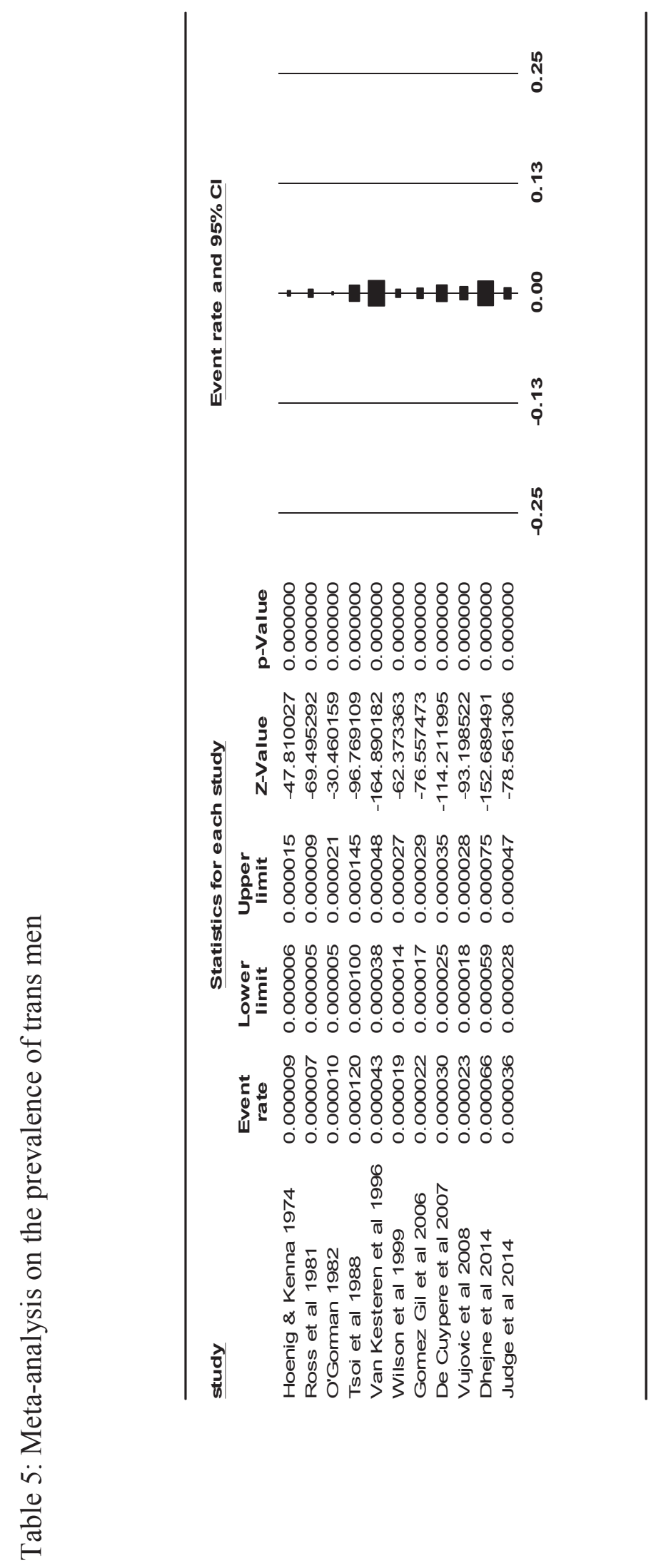




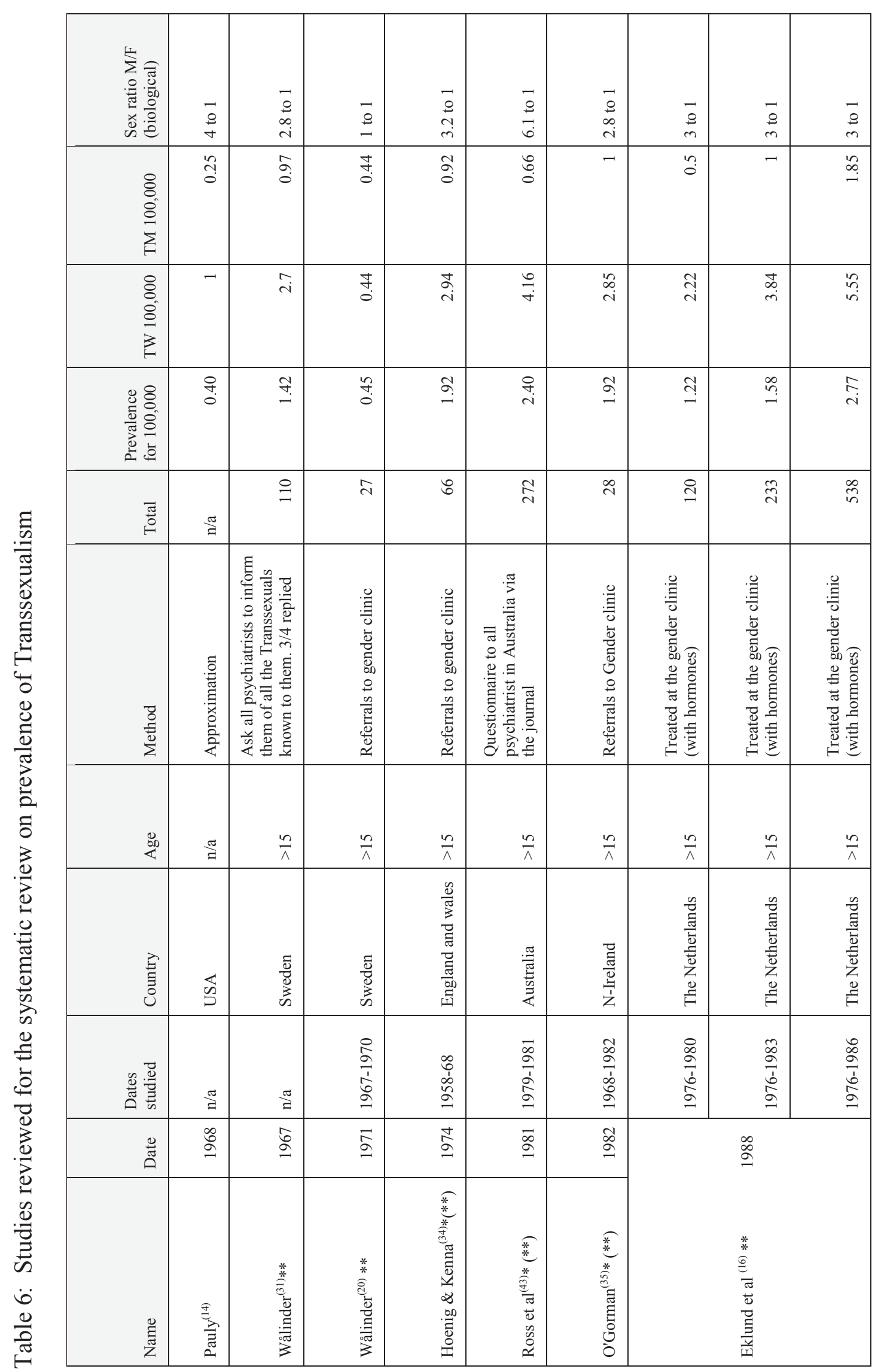




\begin{tabular}{|c|c|c|c|c|c|c|c|c|}
\hline $\begin{array}{l}n \\
n \\
0 \\
0 \\
0\end{array}$ & $\vec{\rho}$ & $\begin{array}{l}\overrightarrow{0} \\
\text { in } \\
i\end{array}$ & $\vec{p}$ & $\begin{array}{l}\vec{\rho} \\
0 \\
i \\
c\end{array}$ & $\begin{array}{l}\overrightarrow{8} \\
\stackrel{+}{+}\end{array}$ & $\overrightarrow{\stackrel{8}{+}}$ & 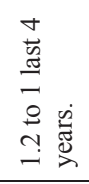 & 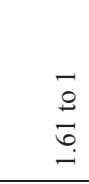 \\
\hline$\stackrel{\pi}{\Omega}$ & $\simeq$ & $\begin{array}{l}\stackrel{\infty}{]} \\
\text { n) }\end{array}$ & $\stackrel{?}{+}$ & ஓ̊ & $\begin{array}{l}\infty \\
i \\
i\end{array}$ & 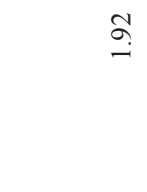 & $\stackrel{\pi}{\Xi}$ & $\stackrel{+}{\stackrel{r}{+}}$ \\
\hline$\stackrel{\Xi}{\nexists ~}$ & in & $\underset{\infty}{+}$ & $\begin{array}{l}\overrightarrow{\mathrm{I}} \\
\underline{\mathrm{I}}\end{array}$ & $\stackrel{\infty}{\stackrel{\infty}{\sim}}$ & 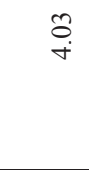 & $\stackrel{\infty}{\stackrel{\infty}{r}}$ & $\stackrel{\Xi}{\Omega}$ & $\stackrel{+}{\stackrel{?}{r}}$ \\
\hline$\stackrel{\pi}{\rightrightarrows}$ & $\begin{array}{l}\dot{0} \\
\ddot{i}\end{array}$ & $\stackrel{\text { If }}{+}$ & $\begin{array}{l}n \\
0 \\
\infty\end{array}$ & $\stackrel{\leftrightarrow}{\stackrel{i}{i}}$ & $\stackrel{\mathcal{F}}{\mathrm{r}}$ & $\stackrel{\overbrace{}}{\stackrel{f}{r}}$ & $\stackrel{\Xi}{\Xi}$ & $\begin{array}{l}\bar{\sigma} \\
\text { nd }\end{array}$ \\
\hline$\stackrel{\circ}{i}$ & $\stackrel{\infty}{\not}$ & $\stackrel{m}{\sim}$ & $\stackrel{\infty}{\alpha}$ & $\stackrel{m}{n}$ & 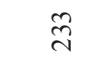 & $\stackrel{8}{\circ}$ & 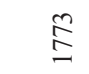 & ช̊ \\
\hline 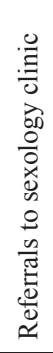 & 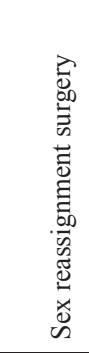 & 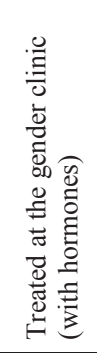 & 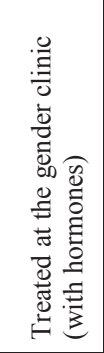 & 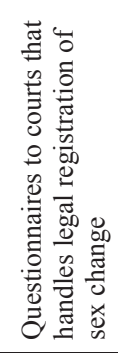 & 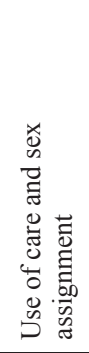 & 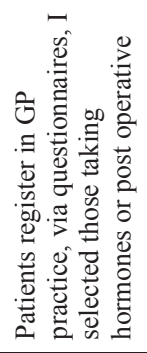 & 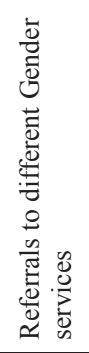 & 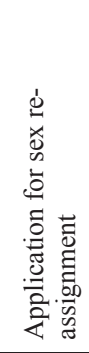 \\
\hline$\stackrel{\Delta}{\Lambda}$ & $\stackrel{n}{\wedge}$ & $\stackrel{n}{\wedge}$ & $\stackrel{n}{\wedge}$ & $\stackrel{\Xi}{\Xi}$ & $\frac{n}{\wedge}$ & $\frac{n}{\lambda}$ & $\stackrel{\Delta}{\Lambda}$ & $\frac{n}{\wedge}$ \\
\hline 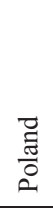 & 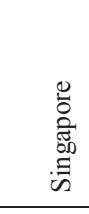 & 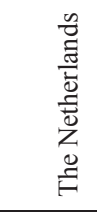 & 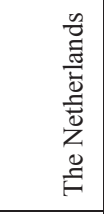 & 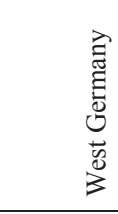 & 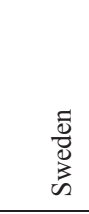 & 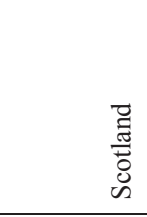 & $\begin{array}{l}\text { ते } \\
\text { है }\end{array}$ & 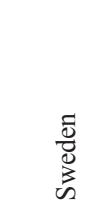 \\
\hline $\begin{array}{l}\frac{\infty}{\mathfrak{1}} \\
\frac{1}{5} \\
\stackrel{a}{a}\end{array}$ & 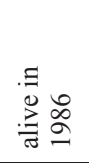 & $\begin{array}{l}\stackrel{2}{\circ} \\
\frac{1}{b} \\
\vdots \\
\vdots\end{array}$ & 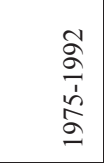 & $\begin{array}{l}\frac{8}{\circ} \\
\frac{1}{10} \\
\frac{0}{9}\end{array}$ & 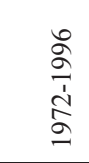 & $\stackrel{\infty}{\stackrel{\infty}{\sigma}}$ & $\begin{array}{l}\frac{\infty}{\circ} \\
\frac{1}{d} \\
\stackrel{d}{\sigma}\end{array}$ & 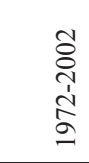 \\
\hline $\begin{array}{l}\infty \\
\stackrel{\circ}{\sigma}\end{array}$ & $\stackrel{\infty}{\stackrel{\infty}{\varrho}}$ & $\stackrel{\Omega}{\Omega}$ & $\stackrel{\circ}{\circ}$ & $\stackrel{\circ}{\circ}$ & よ̊ & $\stackrel{\partial}{\sigma}$ & ષ્ণ & ڤ్రి \\
\hline 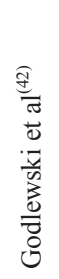 & 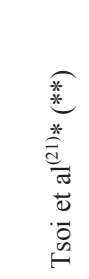 & 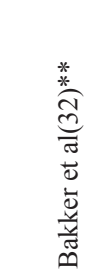 & 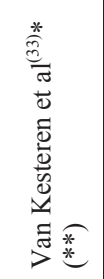 & 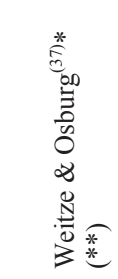 & 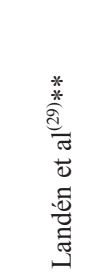 & \begin{tabular}{l}
$*$ \\
\multirow{2}{*}{} \\
$\frac{*}{0}$ \\
$\frac{0}{0}$ \\
$\frac{\pi}{0}$ \\
0 \\
0 \\
0 \\
$\frac{0}{5}$ \\
3
\end{tabular} & 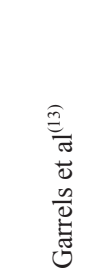 & 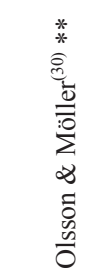 \\
\hline
\end{tabular}




\begin{tabular}{|c|c|c|c|c|}
\hline $\begin{array}{l}\overrightarrow{0} \\
0 \\
0 \\
i\end{array}$ & 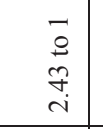 & $\vec{\rho}$ & $\begin{array}{c}\overrightarrow{0} \\
0 \\
0 \\
-\end{array}$ & $\begin{array}{l}\overrightarrow{8} \\
\stackrel{i}{i}\end{array}$ \\
\hline$\stackrel{\grave{i}}{i}$ & $\stackrel{n}{\stackrel{n}{i}}$ & $\widehat{\widehat{\lambda}}$ & $\begin{array}{l}t \\
0 \\
0\end{array}$ & $\overrightarrow{\vec{r}}$ \\
\hline 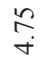 & $\stackrel{\overbrace{}}{\curvearrowright}$ & $\stackrel{\widetilde{\lambda}}{\mathrm{N}}$ & $\begin{array}{l}\stackrel{n}{n} \\
=\end{array}$ & $\begin{array}{l}+ \\
\infty \\
\sigma\end{array}$ \\
\hline $\begin{array}{c}\infty \\
\infty \\
\sim\end{array}$ & $\begin{array}{l}\stackrel{\leftrightarrow}{+} \\
\stackrel{+}{2}\end{array}$ & તై & $\begin{array}{l}\hat{b} \\
\dot{b}\end{array}$ & $\stackrel{\hat{b}}{6}$ \\
\hline$\stackrel{\mathscr{\infty}}{=}$ & 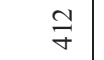 & 守 & $\vec{\infty}$ & $\stackrel{\infty}{\sim}$ \\
\hline 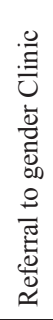 & 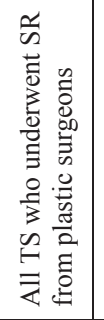 & 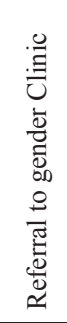 & 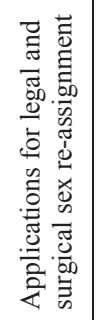 & 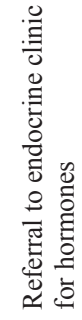 \\
\hline$\stackrel{n}{\wedge}$ & $\stackrel{n}{\wedge}$ & $\stackrel{\infty}{\wedge}$ & $\vec{\lambda}$ & $\stackrel{n}{\wedge}$ \\
\hline 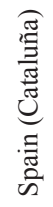 & 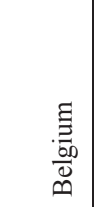 & 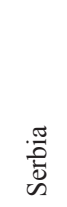 & 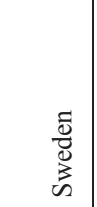 & 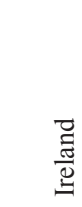 \\
\hline 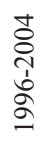 & 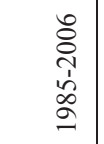 & $\begin{array}{l}8 \\
\stackrel{1}{1} \\
\stackrel{1}{\infty} \\
\stackrel{0}{0}\end{array}$ & 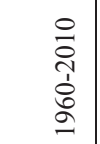 & 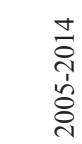 \\
\hline ¿্ণ & $\hat{\stackrel{i}{े}}$ & 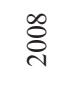 & $\underset{\vec{d}}{\vec{D}}$ & $\stackrel{\vec{i}}{\vec{i}}$ \\
\hline 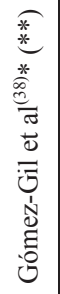 & 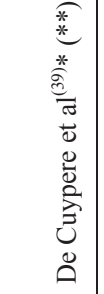 & 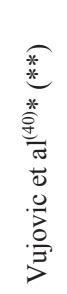 & 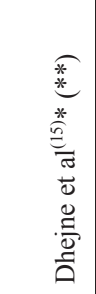 & 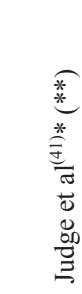 \\
\hline
\end{tabular}

